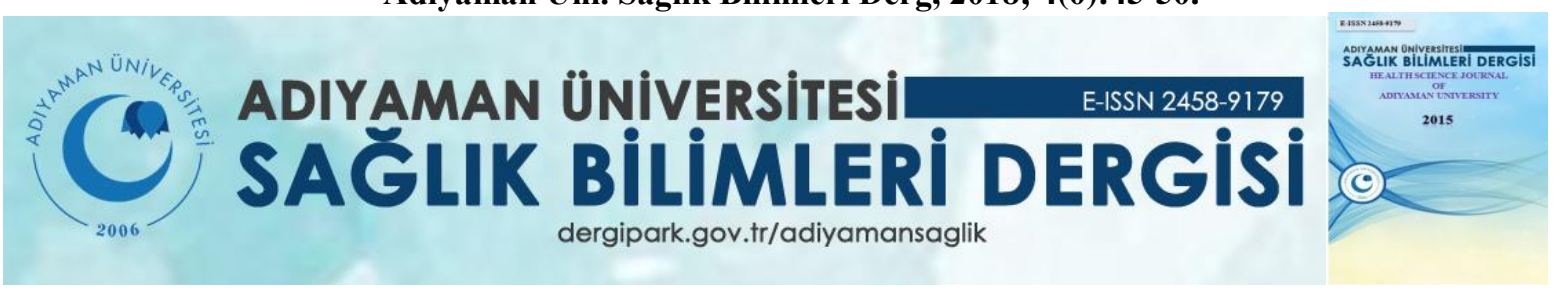

\title{
Olgu Sunumu/Case Report Dikkat Sorunlarında Artış ile Prezente Olan Bir Hashimoto Tiroiditi Olgusu
}

\author{
Mahmut Zabit Kara ${ }^{1}$, Mehmet Hamdi Örüm ${ }^{2}$ \\ ${ }^{1}$ Adıyaman Üniversitesi Eğitim ve Araştırma Hastanesi, Çocuk ve Ergen Ruh Sağlığı ve Hastalıkları, , Adıyaman, Türkiye \\ ${ }^{2}$ Adıyaman Üniversitesi Tıp Fakültesi, Psikiyatri Ana Bilim Dalı, Adıyaman, Türkiye.
}

\section{Özet}

Dikkat Eksikliği Hiperaktivite Bozukluğu (DEHB), son derece önemli akademik, sosyal ve psikiyatrik sorunlara yol açabilen bir hastalıktır. Genetik nedenli olmakla birlikte bazı eşlik eden durumlar kliniğin şiddetlenmesine neden olabilmektedir. Biz bu olgu sunumunda, Hashimoto Tiroiditi gelişen 14 yaşındaki bir kız hastada var olan dikkat eksikliği sorunlarının artışını ele aldık. DEHB'de; ilk başvuruda, tedaviye rağmen belirti şiddetinin azalmadığı ve klinik tablonun kötüleştiği durumlarda medikal açıdan hastanın değerlendirilmesi önem taşımaktadır. Bedensel işaretler ortaya çıkmadan bilişsel fonksiyon ve dikkat becerisindeki kötüleşme ile kendini gösteren Hashimoto Tiroiditi vakası; hastanın bütün olarak ele alınmasının önemini, zihinsel işlevler ile bedensel işlevlerin birbirinden ayrı düşünülemeyeceğini göstermesi bakımından paylaşılmaya değer bulunmuştur.

Anahtar Kelimeler: Biyolojik Psikiyatri, Dikkat Eksikliği Hiperaktivite Bozukluğu, Hashimoto Tiroiditi

\section{A Case of Hashimoto Thyroiditis Presence with Increase in Attention Deficit}

\begin{abstract}
Attention Deficit Hyperactivity Disorder (ADHD) is a disease that can lead to extremely important academic, social and psychiatric problems. Along with being genetically induced, some accompanying conditions can lead to the exacerbation of the clinic. In this case report, we discussed the increase in attention deficit problems in a 14-year-old girl with Hashimoto thyroiditis. In ADHD; in the first application, in cases where symptom severity does not decrease despite the treatment, and if clinical presentation deteriorates, it is important to evaluate the patient in terms of general medical condition. This Hashimoto Thyroiditis case, manifested by the worsening of cognitive function and attention without the emergence of somatic signs suggested the importance of treating the patient as a whole, and that mental functions and bodily functions cannot be considered separately.
\end{abstract}

Key words: Biological Psychiatry, Attention Deficit Hyperactivity Disorder, Hashimoto Thyroiditis

Yazışmadan Sorumlu Yazar

\section{Mehmet Hamdi Örüm}

Adıyaman Üniversitesi Tıp Fakültesi, Psikiyatri Ana Bilim Dalı, Adıyaman, Türkiye, , Adıyaman, Türkiye

Tel : $+\underline{9041621610157-1186}$

Email: mhorum@hotmail.com
DOI:10.30569/adiyamansaglik. 430094

\begin{tabular}{ll}
\hline Geliş Tarihi: & 03.06.2018 \\
\hline Kabul Tarihi: & 25.07 .2018 \\
\hline
\end{tabular}




\section{Giriş}

Dikkat Eksikliği Hiperaktivite Bozukluğu (DEHB), dikkat eksikliği, dürtüsellik ve hareketlilik belirtileri ile giden, bireyin akademik başarısı, aile hayatı, sosyal ilişkileri ve benlik saygısı üzerine çeşitli olumsuz etkileri olan nöropsikiyatrik bir sendromdur (1). Çocukta dikkat sorunları özellikle eğitim hayatının başlamasıyla belirgin hale gelir. Öğrenmeye karşı ilgisizdirler. Bu çocuklarda anksiyete bozuklukları, depresif şikayetler görülebilmektedir. Okul ve aile hayatlarında sorumluluklarını yerine getirmekte güçlük çekmelerine neden olabilecek alkol-madde bağımlılıklarına sık rastlanır ve bu sorun ilerleyen yaşlarda da ciddi bir sorun olarak devam edebilmektedir (2-4). DEHB'nin etiyolojisi tam olarak bilinmemektedir. Diğer psikiyatrik hastalıklarda da olduğu gibi biyo-psiko-sosyokültürel nedenlerin DEHB'nun ortaya çıkmasında rol oynadığı düşünülmektedir. Gebeliğginde iyot eksikliği görülen gebelerin çocuklarında DEHB sıklığında artış bildirilmiştir (5). DEHB semptomları, bazı eşlik eden durumlarla şiddetlenmektedir. Gelişimsel bozukluklara otoimmün bozuklukların eşlik edebildiği bilinmektedir. DEHB ile immün system üzerindeki bağlantı sitokinler ve sitokin gen polimorfizmleri üzerinden açıklanmaya çalışılmıştır. Avcil çalışmasında, inflamasyonun DEHB etiopatogenezinde rol alabileceğini ve nötrofil/lenfosit oranı ve monosit/lenfosit oranı gibi parametrelerin potansiyel DEHB belirteci olabileceğini belirtmiştir (6). Eşlik eden, birbirini etkileyen bu olası tıbbi durumlar ile psikiyatrik bozuklukların ayırımının tedavi açısından önemi büyüktür. Biz bu olgu sunumunda, Hashimoto Tiroiditi gelişen bir hastada, var olan dikkat eksikliği ile ilişkili sorunların artışını ele aldik. 


\section{Olgu Sunumu}

14 yaşında kız hasta. 6 ay önce başlayan ve devam eden artmış odaklanma güçlügü, unutkanlık, dalgınlık şikâyetleri ile başvurdu. İlkokul yıllarında dış merkez değerlendirmesinde DEHB tanısı ile takip edilmiş ancak ilaç tedavisi almamış. Son 6 ay içinde işlevselliğinde ciddi bir düşüş olması üzerine, öğretmenlerinin önerisi ile getirilmiş. Yapılan ruhsal değerlendirme sonucunda DSM-5'e göre DEHB tanı kriterlerini karşıladığı saptandı. DEHB ile ilişkilendirilen ana semptom dikkati sürdürmekte güçlüktü. Conners Ana Baba Derecelendirme Ölçeği’nde (CABDÖ); dikkat eksikliği:13, hiperaktivite: 1, karş1 gelme:1, davranım sorunları: 4 puan olarak saptandı. Eşlik eden psikopatoloji saptanmadı. Beck Depresyon Ölçeği'nde: 3 (minimal düzeyde belirtiler), Beck Anksiyete Ölçeği'nde: 5 (minimal düzeyde belirtiler) görüldü. Vücut kitle indeksi 23'tü. Rutin kan tahlillerinde; sT4: 0.37 pg/ml (0.61-1.48), TSH: 49.3 mIU/L (0.34-5.6) olarak görüldü. Diğer parametreler normal sınırlardaydı. Pediatrik endokrinoloji uzmanı tarafından değerlendirilen hastaya; Anti TPO: 1048 (0-5.61), Anti TG: 10.8 (0-4.18) değerlerine sahip olması nedeniyle Hashimoto Tiroiditi teşhisi ile levotiroksin sodyum $50 \mathrm{mcg} /$ gün başlandı. Unutkanlık ve konsantrasyon güçlügü tiroid fonksiyonlarında bir bozukluk olabileceğini düşündüren başlıca semptomlardı. Hastanın 2 ay sonraki kontrolünde ötiroid olduğu saptandı, ilaç tedavisinin devamı planlandı. Aynı dönemde yapılan ruhsal durum muayenesinde, hastanın hala DEHB tanı kriterlerini karşılamakla birlikte belirti şiddetinin azaldığı ve eski işlevselliğine döndüğü öğrenildi. CABDÖ'de; dikkat eksikliğgi: 5, hiperaktivite:1, davranım sorunları: 3, karşı gelme: 1 olarak belirlendi. Hasta ilaç kullanımı olmadan takibe devam etmekte ve benzer şikâyetleri olmadığı bildirilmektedir. $\mathrm{Bu}$ yazının yazılması için hastanın ebeveynlerinden aydınlatılmış onam alınmıştır. 


\section{Tartışma}

DEHB nedeni bilinmeyen heterojen bir bozukluktur. Konu ile ilgili araştırmalar, genetik, beyin görüntüleme, nörokimyasal değişiklikler ve psikososyal nedenleri belirlemeye yönelik olarak sürdürülmektedir. DEHB'nin nörobiyolojisinde nörotransmitterlerin metabolizmasında bozukluğa yol açan genler üzerinde durulmaktadır. Tiroid reseptor $\beta$ geni araştırılan bu genlerden biridir. Tiroid hormonuna genel direnci olan erişkin hastaların \%42'si DEHB tanısı almışlardır. Tiroid hormonu replasman tedavisi ile davranışsal belirtilerin bir kısmı düzelmiş ve bu veriler DEHB'deki genetik yatkınlığın bir kısmından mutant tiroid reseptörlerinin sorumlu olabileceğini düşündürmüştür. Dopamin resptör genleri (DRD2, DRD4, DRD5) ve dopamin taşıyıcı geni (DAT) ise diğer bazı ilişkili genlerdir (7). Hem tiroid hastalıklarında hem de DEHB'de ortak olarak görülebilen belirtiler (dikkati sürdürmekte güçlük, irritabilite, sinirlilik, depresyona yatkınlık) nedeniyle her iki hastalık birbirinin ayırıcı tanısında yer alabilir $(8,9)$. Bu yüzden DEHB tanı öncesinde ve tedavi sırasında tiroid hormonlarına ait değerlerin takibi ve subklinik hipotiroidinin dışlanması önemlidir (8). Hashimoto Tiroiditi hastalarının nörobilişsel fonksiyonlarında sıklıkla bozukluk ortaya çıkmaktadır. $\mathrm{Bu}$ durumun altında yatan mekanizmanın tiroid fonksiyonlarından bağımsız olduğu bilinse de tam olarak açıklanamamıştır. Yine de bu durumun immünolojik mekanizmalardan kaynaklandığı düşünülmektedir (10).

DEHB'li her olguda farklı bir neden etkili olabileceği gibi, aynı olguda farklı etkenler bir arada bulunabilmektedir. Genel olarak kabul edilen görüşe göre ise DEHB farklı patolojilerin ortak semptomatolojisidir. Bir organizmada ortaya çıkabilecek davranışsal belirtilerin sayısı sınırlıdır. Genetik yüklülük, doğum öncesi ya da sonrasında ortaya çıkan travmalar ve diğer etkenlere bağglı olarak beyinde oluşabilecek çok çeşitli bozukluklar sonuçta benzer davranışsal belirtilere neden olabilirler (6). 
DEHB tedavisi psikoeğitim, davranış tedavisi ve farmakoterapiyi içerir. Altta yatan biyolojik nedene yönelik ilaç kullanımı yaygın bir yöntemdir. Bu amaçla psikostimülanlar, seçici noradrenalin geri alım inhibitörleri, adrenerjik ajanlar, antidepresanlar ve dopaminerjik ajanlar tek ve kombine olarak kullanılabilir. Ancak bazı hastalar ilaç tedavisine vermemekte veya beklenenden az yanıt vermektedir. DEHB'de; ilk başvuruda, tedaviye rağmen belirti şiddetinin azalmadığı ve klinik tablonun kötüleştiği durumlarda medikal açıdan hastanın değerlendirilmesi önem taşımaktadır $(4,5,7)$. Bedensel işaretler ortaya çıkmadan bilişsel fonksiyon ve dikkat becerisindeki kötüleşme ile kendini gösteren Hashimoto tiroiditi vakası; hastanın bütün olarak ele alınmasının önemini, zihinsel işlevler ile bedensel işlevlerin birbirinden ayrı düşünülemeyeceğini göstermesi bakımından paylaşılmaya değer bulunmuştur.

Finansal Destek ve Çıkar Çatışması: Yazarlar finansal bir destek almadıklarını ve aralarında herhangi bir çıkar çatışması bulunmadığını beyan etmişlerdir.

Yazar Katkıları: Yazar 1; süpervizyon, kaynak, materyal, veri toplama, analiz, yazım, kritik eleştiri; Yazar 2; dizayn, veri işleme, literatür taraması, yazım.

Teşekkür: Hasta ve ailesine teşekkürü bir borç biliriz. Bu makaledeki bilgilerle bu hastanın kimliğine dair bir saptama yapılması olanaksızdır. Makalenin yayınlanması için hasta ve ailesinden gerekli aydınlatılmış onam alınmıştır. 


\section{Kaynaklar}

1. Naguy A. Psychopharmacotherapy of attention deficit-hyperactivity disorder in children with comorbid conditions. Pediatr Neurol 2018;82:7-12.

2. Orum MH, Kara MZ, Egilmez OB, Kalenderoglu A. Complete blood count alterations due to the opioid use: what about the lymphocyte-related ratios, especially in monocyte to lymphocyte ratio and platelet to lymphocyte ratio? J Immunoassay Immunochem 2018;14:1-12.

3. Orum MH, Kustepe A, Kara MZ, Dumlupinar E, Egilmez OB, Ozen ME, Kalenderoglu A. Addiction profiles of patients with substance dependency living in Adiyaman province. Med Sci in press. doi: 10.5455/medscience.2018.07.8752.

4. Orum MH, Bildik T, Kara MZ, Yilmaz H, Tahillioglu A, Kalenderoglu A. High functioning autism or Asperger's disorder follow-up period: Detailed retrospective evaluation and novel status determination of a case and prospective guidance. Journal Mood Disorders in press. doi: 10.5455/jmood.20171205113628.

5. Hatipoğlu N, Büyükkayhan D, Kurtoğlu S. Yenidoğan dönemi tiroid hastalıkları. Turkiye Klinikleri J Pediatr Sci 2006;2(10):63-82.

6. Avcil S. Evaluation of the neutrophil/lymphocyte ratio, platelet/lymphocyte ratio, and mean platelet volume as inflammatory markers in children with attention-deficit hyperactivity disorder. Psychiatry Clin Neurosci 2018;72(7):522-530.

7. Öncü B, Şenol S. Dikkat eksikliği hiperaktivite bozukluğunun etiyolojisi: Bütüncül yaklaşım. Klinik Psikiyatri 2002;5:111-119.

8. Şengül C, Dilbaz N, Üstün İ, Balc1-Şengül C, Okay T. Subklinik hipotiroidinin eşlik ettiği bir periyodik katatoni olgusu. Anadolu Psikiyatri Dergisi 2005;6:57-59.

9. Radesky J. Digital media and symptoms of attention-deficit/hyperactivity disorder in adolescents. JAMA 2018;320(3):237-239.

10. Leyhe T, Müssig K, Weinert C, Laske C, Häring HU, Saur R, et al. Increased occurrence of weaknesses in attention testing in patients with Hashimoto's thyroiditiscompare d to patients with other thyroid illnesses. Psychoneuroendocrinology 2008;33(10):1432-1436.

11. Cantwell DP. Attention deficit disorder: A review of the past 10 years. J Am Acad Child Adolesc Psychiatry 1996;35:978-986.

12. Morrill MS. Special education financing and ADHD medications: A bitter pill to swallow. J Policy Anal Manage 2018;37(2):384-402. 